\title{
Research on the Development and Application of Teaching Resources Sharing Platform in Higher Vocational Colleges
}

\author{
Haihuai He \\ Wenzhou Vocational \&amp; Technical College China Zhejiang Wenzhou 325035
}

Keywords: Higher vocational colleges; Resource sharing platform; Development and application

\begin{abstract}
China's Ministry of education has made it clear that for those covering area widely, the demand for larger professional, the relevant departments have the funding to improve the construction of teaching resources sharing platform and teaching resource library. With the continuous expansion of the scope of application of information technology, higher vocational colleges teaching methods also continuously toward the direction of three-dimensional development. Under this background, the development and application of teaching resources in higher vocational colleges is in is particularly important.
\end{abstract}

\section{Introduction}

The so-called teaching resources sharing platform is the information technology as the main channel, through the network the education teaching resources were collected, which need to be online watch or download, and can be completed online communication of a comprehensive information management system. It can be said that the teaching resources sharing platform has a variety of characteristics of today's network platform, not only can the teaching resources digitization, information, but also can make it share and intelligent interaction. The sharing platform of teaching resources makes it better integrated into the current teaching work, which greatly promotes the progress of the education and teaching reform, and puts forward the guiding suggestions for the future education and teaching work. Therefore, how to higher vocational colleges, teaching philosophy and teaching resources sharing platform integration, make full use of the current resources of information technology, construct a meet the needs of the current education and teaching resources sharing platform will undoubtedly become an important task of higher vocational colleges teaching efficiency and water [1].

\section{The Significance of the Development and Application of Teaching Resources Sharing Platform in Higher Vocational Colleges}

Teaching resources sharing platform for the reform of teaching work in higher vocational colleges has a very important significance, which can be as an important springboard of the reform of education and teaching, through the network and information technology in education and teaching in the application of the results for the education and teaching in the future development to pave the way.

Promote the Sharing of High Quality Teaching Resources. The sharing of teaching resources sharing platform in higher vocational colleges is the excellent teaching case that the current excellent teachers or experts and scholars have done. When the class teaching through the teaching resources sharing platform for higher vocational colleges, we can make a lot of advanced teaching ideas to break through the time and space constraints, to achieve long-distance communication. Every higher vocational college has its own outstanding subject and by higher vocational colleges teaching resources sharing platform can give full play to the their own expertise, absorption and other excellent colleges, teaching staff, teaching philosophy and teaching methods, learn from each other. In addition, through teaching resources sharing platform can also broaden the radiation surface of the audience of the higher vocational education, the current school education through the Internet into social education, improve the social humanistic quality and culture. For those areas with relatively poor teaching resources, we can also transfer the teaching resources through the 
sharing platform of teaching resources, to avoid the occurrence of the differences in regional teaching level. Many social workers to learn professional knowledge craving and students compared to succeed not to, but always lack learning conditions and vocational colleges teaching resource sharing platform for application development and undoubtedly can effectively compensate for this deficiency.

Promote the Diversified Development of Teaching Work. In the traditional teaching work in higher vocational colleges, education and teaching has been the teacher to teach the content of the course, and students in the stage of passive memory. Although this teaching method has been extended for a long time, the teaching effect is not satisfactory. The emergence of teaching resources sharing platform not only can effectively improve the quality of teaching resources, but also can make teaching more development direction. For example: by teaching resources sharing platform, students can more efficient preparation before class and review after class; can through to other colleges and universities teaching resources to carry on the analysis to fill gaps and lack of investigation; can have more channels to understand the latest research achievements of the professional. The traditional way of teaching through teaching continuum to ensure teaching quality, and through the teaching resources sharing platform can be through the broader marine resources to enhance the students' learning efficiency, results of the two teaching methods have been able to will undoubtedly have a more obvious differences.

Promote the Automation And Standardization of Teaching Management. Teaching resources sharing platform not only can input, output, retrieval and dissemination of high quality teaching resources, but also can complete the work of distance teaching and online teaching. Phase, compared with the traditional way of teaching, the teacher can more effectively the master students to learn the actual situation, manages the student information, also can through the software platform of the homework and exam arrangement, and complete the automatic correcting and automatic recovery work. In addition, the use of teaching resources sharing platform can also make the teaching work more diverse and rich, the use of multimedia in teaching will be more extensive. Teaching resources sharing platform for teaching work, not only can use the conventional text teaching, but also can make pictures, video, audio and other fully utilized. And in the operation of the preparation, you can choose a reasonable choice, fill in the blank, the number of concepts and discusses the title, in order to achieve the flexible development of the form [2].

\section{Development and Application Strategy of Teaching Resources Sharing Platform in Higher Vocational Colleges}

Since the sharing platform of teaching resources in higher vocational colleges has been put forward, it has been highly valued by experts and scholars in the field of domestic related fields, and it has set off a boom of its development and application in our country. Before our country has already carried on the network and the information technology teaching reform, such as "the micro lesson", is based on the complete curriculum framework and the establishment of the network course teaching mode. Through the practice of network teaching resource sharing, we can clearly understand the current problems and future development direction of teaching resources sharing platform in Higher Vocational colleges.

Development Status of Teaching Resources Sharing Platform in Higher Vocational Colleges. First of all, the most important platform for the development of teaching resources sharing platform is the choice of the platform. The current network platform in the development process of design work is relatively poor, and not in view of the current higher vocational colleges and the actual needs of the teaching resource planning, most of them are still will upload resources to the network, and there is no effective planning and classification. Secondly, the main object platform: teaching resource quality uneven in quality teaching resources sharing. Although the current teaching resource sharing platform has been put into use, but it has not been popularized. Many teachers in the use of teaching resources sharing platform or the use of a simple ppt or word documents, and not the perfect integration of multimedia teaching content. In addition, most of the current use of the platform is also not perfect, some of the uploaded files in a long time will often occur after the loss. 
If the person does not have a backup, the teaching resource will never be restored. If users on the platform of the specific use of the method is not enough to understand, even if it is simple to download and upload work is difficult to carry out. Finally, most of the current use of teaching resources sharing platform does not follow the maintenance of work. After it is put into use, the staff in the background will not be on the platform for a long time to review the teaching resources, screening and updating. This also led to the platform of teaching resources in the presence of duplication, outdated content, which led to the gradual reduction of the use rate, and ultimately abandoned by the user.

Development and Application of Teaching Resources Sharing Platform in Higher Vocational Colleges. First of all, the development of teaching resources sharing platform in higher vocational colleges is a systematic project. If it is just a series of materials without the law of the stack of the database, it completely deviated from the original intention of the construction of the class platform. So in order to effectively improve the efficiency of the teaching resources sharing platform, we must take advanced teaching concept as the guiding ideology in the construction of the platform. In the field of modern teaching, there is still a big gap between our country and the western developed countries, so we can learn from foreign teaching concept to know the development of teaching resources sharing platform in higher vocational colleges. Of course, the actual teaching situation of foreign teaching idea and our country will inevitably exist some differences, so we can't completely copy must be according to the teaching resources sharing platform development and construction of the actual needs of the corresponding modification, draw lessons from social investigation results, in order to introduce the teaching philosophy is proposed for platform structure design of our country's educational environment.

Secondly, we should improve the overall quality of the teaching resources. For higher vocational college teaching resources sharing platform, the quality of teaching resources is the core of the platform. To effectively improve the practicality of teaching resources sharing platform, it is needed to improve the quality of teaching resources in the platform. Now is the information age, the traditional teaching resource type has not been able to meet the current needs of students for the education and teaching work. Only let teaching resources and multimedia technology organic combination, let a single text teaching way transformation fusion of multi elements in the text, video, audio, images, and other teaching methods can effectively improve the quality of teaching resources, so as to meet the actual demand of the users on the platform. Generally speaking, whether or not the teaching resource users can meet the needs of other users is not known to their own teaching resources. Therefore, the platform operators must be carried out to control, reduce the quality of the teaching resources of the upload rate, and regularly review the teaching resources in the platform, delete outdated or repetitive teaching resources.

In addition, in order to ensure the normal use of teaching resources sharing platform, staff must select a more stable network platform as a framework. According to the role of teaching resources sharing platform, we can see, the need to meet the needs of high quality teaching resources of a lot of upload and download the work, also each user will also on the platform of teaching resources online viewing. If the platform itself to use more complex, it will affect the internal quality content to play; if teaching resources sharing platform is not stable enough, may in browsing a large amount of time the collapse of the platform, thus affecting the use of all users experience. Not only that, although the platform is just as a carrier of quality teaching resources, but it should also have a strong appreciation and personalized design, so as to meet the needs of users of the aesthetic. Therefore in the platform to build, but also need to take into account the platform interface design, the layout of each column section, etc.

Finally, the teaching resource sharing platform in higher vocational colleges still needs to carry on the follow-up maintenance and the market promotion after the investment is put into use. Teaching resources sharing platform in the current market environment permits can be said to have occupied a more active position, because it can better meet the various needs of users. But in various teaching resources sharing platform still exists between the very intense competitions, if the platform does not have good web design, there is no simpler to use, no more high-quality teaching 
resources or not good follow-up service, the potential to lose user groups in the platform, thus becoming a shell. In order to the vitality can effectively improve the vocational colleges teaching resource sharing platform, before the platform design needs of all social groups of questionnaire and interview, determine the main demand and secondary demand and avoid platform design and the actual needs of users out of touch. Not only those, after the platform was officially put into use, but also need to be updated according to the situation of the market feedback.

\section{Summary}

With the continuous development of education and teaching reform, information technology teaching has become an indispensable part of the current teaching work. The teaching resource sharing platform, as a good practice project of information teaching and network teaching, will provide a richer experience for the further reform of the teaching work after being put into use. Teaching resources sharing platform is a long-term work, only adhere to investment, joint efforts to develop and explore, to achieve the best results, and improve their teaching ability and social service capabilities.

\section{References}

[1] Liuying, I wish Xiying, regional higher vocational colleges and universities teaching resources sharing research $[\mathrm{J}]$. Value engineering, value engineering, 2011-30 (8)

[2] Zhao Yuepin, Wang Suying, Xue Hui, Hebei province higher vocational colleges quality teaching resources sharing status and strategy research, [J], education and teaching forum, Jiaoxue Luntan Jiaoyu, 2015-2 